\title{
IDENTIFICATION OF BIOACTIVE COMPOUNDS BY GAS CHROMATOGRAPHY-MASS SPECTROMETRY ANALYSIS OF SYZYGIUM JAMBOS (L.) COLLECTED FROM WESTERN GHATS REGION COIMBATORE, TAMIL NADU
}

\author{
DEVAKUMAR J, KEERTHANA V, SUDHA SS* \\ PG and Research Department of Microbiology, Dr. N.G.P. Arts and Science College, Coimbatore, Tamil Nadu, India. \\ Email: drsudhakrish@gmail.com
}

Received: 03 October 2016, Revised and Accepted: 15 October 2016

ABSTRACT

Objective: The aim of this study was to investigate the presence of bioactive compounds in the methanolic leaf extract of Syzygium jambos.

Methods: Collected leaves were shade dried and made into fine powder, extracted with methanol, and the methanolic extract was prepared and analyzed for the presence of bioactive compounds by gas chromatography-mass spectrometry (GC-MS). The mass spectrum of the chromatography was matched with NIST and WILEY Libraries.

Results: The GC-MS analysis revealed the presence of 45 active compounds in the extract. From the GC-MS investigation, 1-Deoxy-d-mannitol 3-methyl-2-methylsulfanyl-5-nitro-6-pyridin-4-ylpyrimidin-4-one, 3-Pentadecylphenol, 2-biphenylene carboxylic acid, Quinoline-3-carboxylic acid, and Stigmast-5-en-3-ol are important phytoconstituents which have antipyretic and antiparasitic activities.

Conclusion: The present investigation revealed preliminary information on phytocompounds presented in $S$. jambos leaf extract which is very useful for the human community.

Keywords: Syzygium jambos, Gas chromatography-mass spectrometry analysis, 1-Deoxy-d-mannitol, Phytoconstituents, Methanolic leaf extract.

(C) 2017 The Authors. Published by Innovare Academic Sciences Pvt Ltd. This is an open access article under the CC BY license (http://creativecommons. org/licenses/by/4. 0/) DOI: http://dx.doi.org/10.22159/ajpcr.2017.v10i1.15508

\section{INTRODUCTION}

Herbal plants are cherished gift of nature for mankind and these plants harbor various phytoconstituents which are used by people around the world have healed the sick with plant-derived medicines and handed over to the next generation. Medicinal plants are capable of synthesizing variety of organic compounds with low molecular weight (MW) which is called as secondary metabolites, which are usually with unique and complex structures [1], and it is used as traditional medicine to maintain healthiness, as well as to inhibit, identify, and recover physical and mental illnesses for human and animal [2]. These medicinal products directly acted as medicine or as a source for modern drug development for various fungal and bacterial infections, an antimalarial drug, and anticancer drugs [3-5]. In recent decades, it increases the pharmacological evaluation of phytoconstituents and their medicinal values [6,7]. Many modern methods were used for identification and quantification of bioactive compounds in plant materials. Rather than, gas chromatography-mass spectrometry (GC-MS) has become confidently developed as a key scientific platform for low molecular (secondary) metabolite profiling in both plant and animal species $[8,9]$.

Syzygium jambos (L.) (Myrtaceae) is a small tree, popularly known as 'Rose apple which is cultivated throughout India for the edible fruit (black plum) and is testified to contain gallic acid, vitamin C, cyanidin, tannins, anthocyanins, and other components [10,11]. For diabetes mellitus, the leaf extract is used as a remedy in many countries [12,13]. Homeopathic medicine is prepared from the seeds and used as a drug in clinical conditions such as acne, pimples, heartburn nausea, headache, abdominal colic, diarrhea, and fever $[14,15]$. In the novelty of this study, the previous researchers have studied the preliminary phytochemical analysis and bioactivity of this plant against clinical pathogens, but in our present study, it is designed to explore the bioactive compounds by GC-MS presented in the methanolic leaf extract of S. jambos.

\section{METHODS}

Collection and authentication of plant leave

$S$. jambos leaves were collected from Semmedu (Fig. 1) (Western Ghats's region), Coimbatore, Tamil Nadu, South India. Identification and authentication was done at Botanical Survey of India (BSI) (South Zone), Coimbatore, India. The voucher specimen was deposited in the Laboratory, Department of Microbiology, Dr. N.G.P. Arts and Science College, Coimbatore.

\section{Preparation of leaf extract}

Collected leaves were washed with water, chopped, and shade dried. The dried leaves were made fine power and used for extraction. Before extraction, the leaf powder $(10 \mathrm{~g})$ was defatted with hexane. The defatted leaf powder was extracted with methanol by cold maceration method for 48 hrs. The mixture was filtered and concentrated by rotary vacuum evaporator. The extract was stored in the refrigerator for further use.

\section{GC-MS analysis for bioactive compounds}

GC-MS analysis was performed at PSG College of Arts and Science, Coimbatore India. $5 \mathrm{ml}$ of methanolic leaf extract was dried and few micrograms was dissolved in $1 \mathrm{ml}$ methanol and the extract was analyzed with GC-MS. Separation process was carried out with CE GC 8000 top MSMD 8000 Fyson instrument with Db $35 \mathrm{mr}$ column (10 $\mathrm{m} \times 0.5 \mathrm{~mm}, 0.25 \mathrm{~mm}$ film thickness). For separation, heating programs were executed with the help of helium carrier gas from 100 to $250^{\circ} \mathrm{C}$ for 3 minutes at the flow rate of $1 \mathrm{ml} / \mathrm{min}$ in the split mode (1:50). An aliquot $(2 \mu \mathrm{l})$ of methanol extract was injected into the column with the injector heater at $250^{\circ} \mathrm{C}$.

\section{Identification of components}

The mass spectra of compounds in the sample were attained by electron ionization (E1) at eV, and the detector operated in scan mode from 20 
to 600 atomic mass units. Molecular structure, molecular mass, and fragmentations were used for identifications. The phytoconstituents were identified with the help of standard mass spectral database of WILEY and NIST Libraries [16,17].

\section{RESULTS}

In the present study, the collected plant was identified and authenticated as $S$. jambos (BSI/SRC/5/23/2012/Tech.1270) in BSI, South zone, Coimbatore, Tamil Nadu, India.

\section{GC-MS analysis}

The methanolic leaf extract of $S$. jambos was analyzed for the presence of phytocompounds by GC-MS as shown in Fig. 2 .

Totally, 45 effective compounds were identified from the chromatogram. The bioactive compounds were predicted by their retention time (RT), peak area percentage (\%), MW, molecular formula, and their biological activities with the help of PubChem Compound (NCBI), Wiley and NIST Libraries (Table 1).

The first active compound 4-Quinolinol,4-ethenyl-1-ethyldecahydro2-methyl-(2.alpha.,4.alpha.,4a.alpha.,8a.beta.) was identified in less RT (5.472) (0.10\%), and the last compound Stigmast-5-en-3-ol was identified in much longest RT (46.573) and high percentage peak area (3.97) was observed. Among these 45 compounds, too many phytocompounds having different biological activities, rather than the compounds categorized in different forms based on their biological activities such as antipyretic, antiparasitic (antimalarial), antibacterial, antifungal, and antiviral compounds, are shown in Tables 2 and 3. 4-Methylbenzyl chloride was observed in the 16.117 RT which showed anticancer activity and used as a drug for genital disorders. No biological activity was reported for the compounds of RT1-3, 7, 8, 10, 15, 16, 17, 19, 20, 24, 27, 28, 31-34, 41 (Table 1).

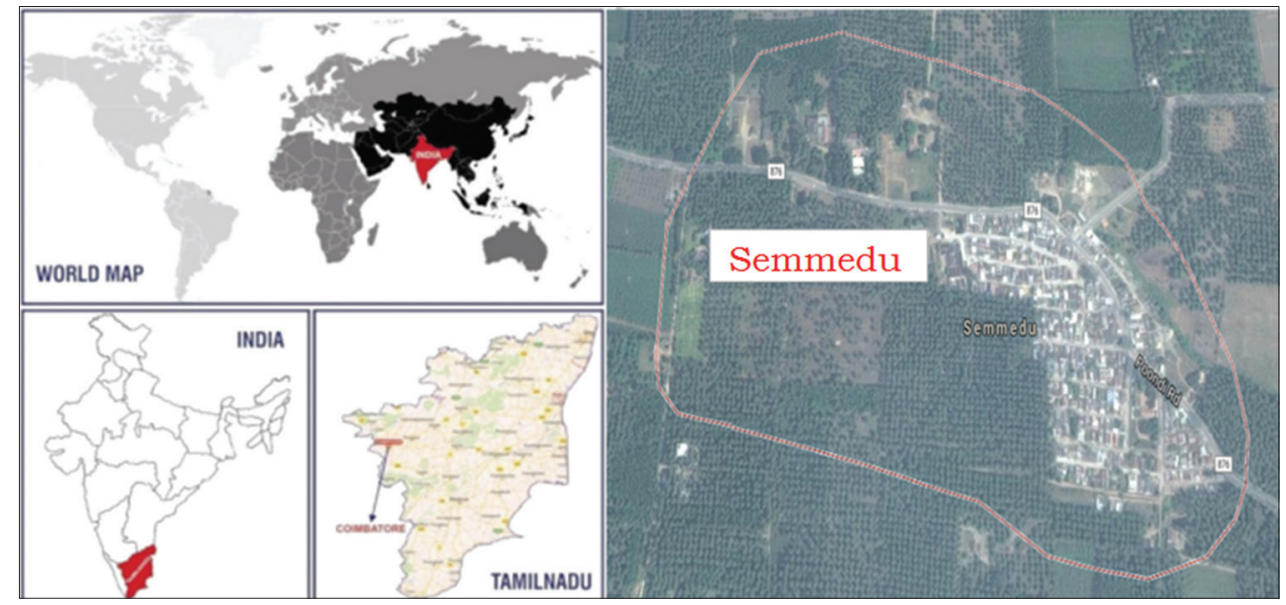

Fig. 1: Map showing the place where leaf samples were collected

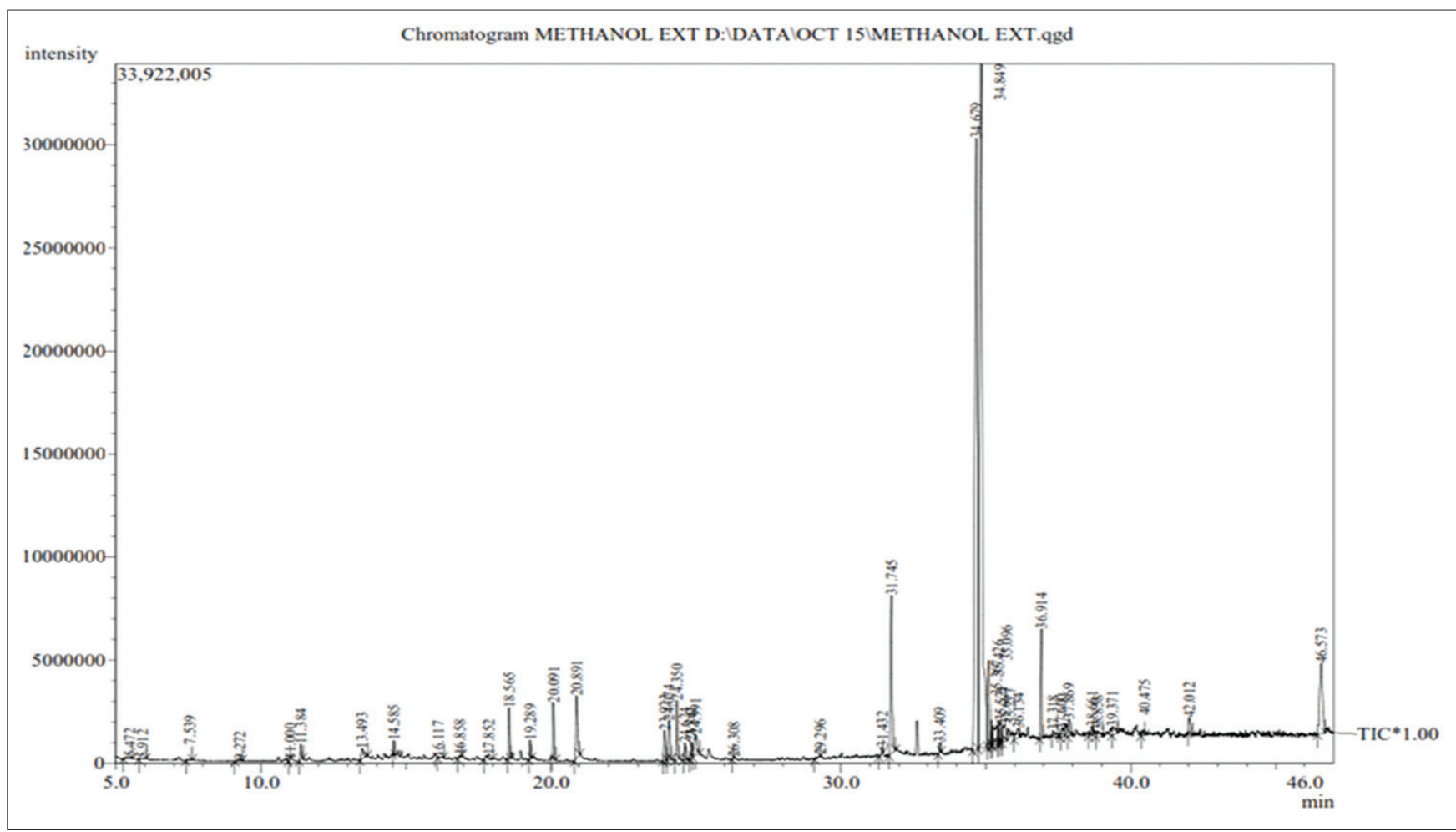

Fig. 2: Gas chromatography-mass spectrometry spectrum of methanolic leaf extract of Syzygium jambos 
Table 1: Phytocompounds present in the methanolic leaf extract of Syzygium jambos

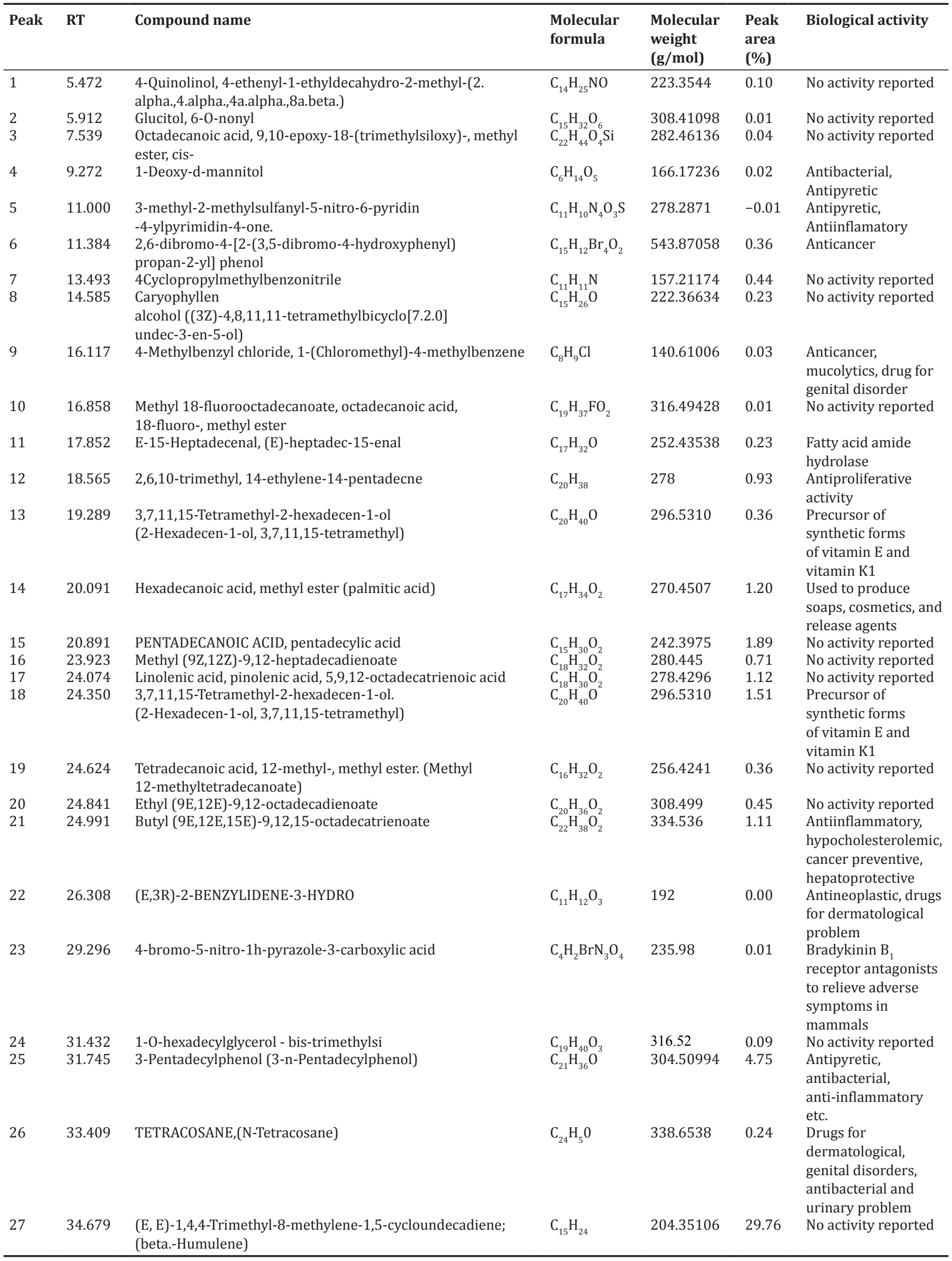


Table 1: (Continued)

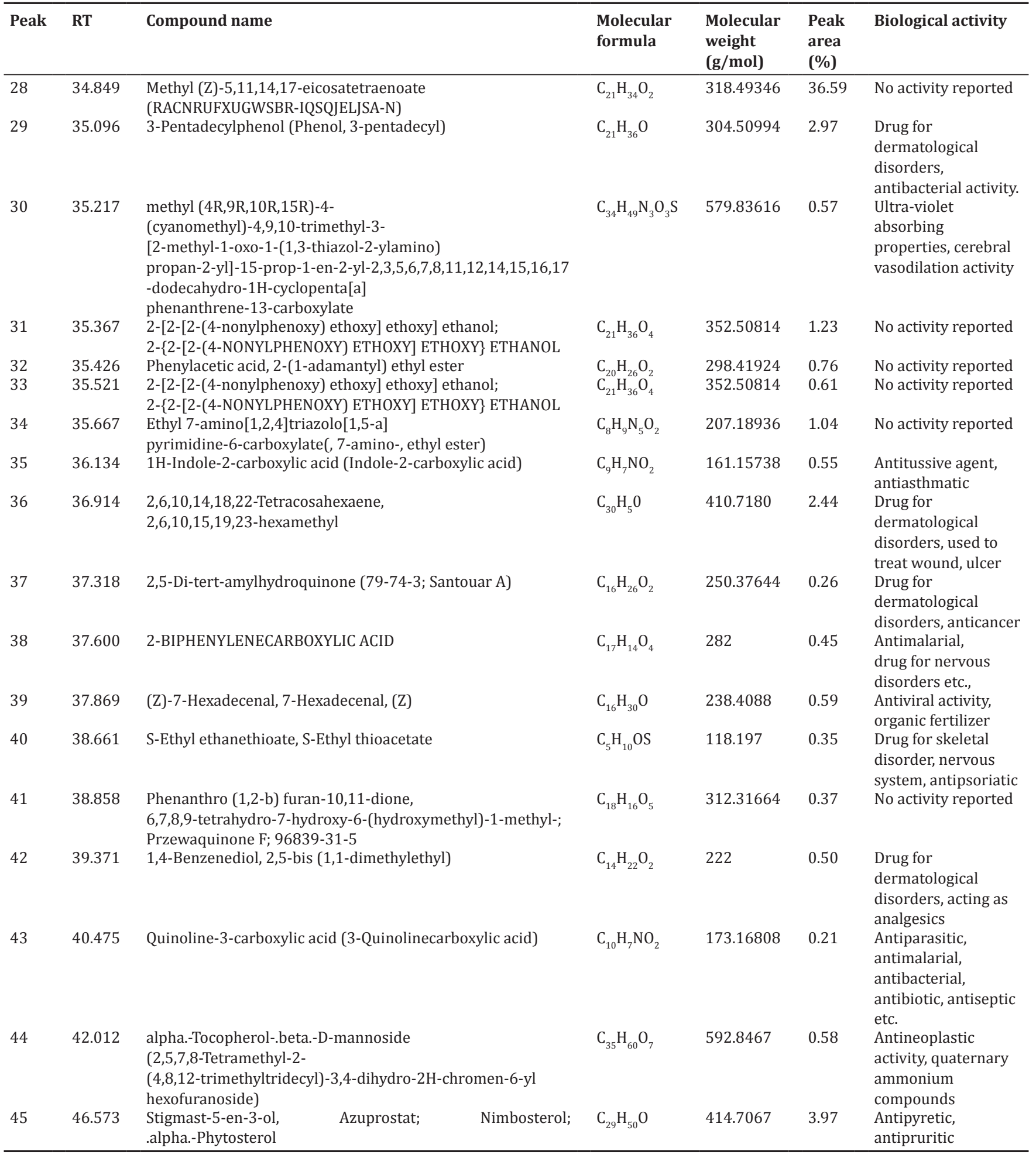

From these 45 active compounds, six phytocompounds exhibited antipyretic and antiparasitic (antimalarial) (Table 2) activity such as 1-Deoxy-d-mannitol (C6H1405), 3-methyl-2-methylsulfanyl5-nitro-6-pyridin-4-ylpyrimidin-4-one (C11H10N403S), 3-Pentadecylphenol (C21H360), 2-biphenylene carboxylic acid (C17H1404), Quinoline-3-carboxylicacid (C10H7NO2), and Stigmast5-en-3-ol (C29H500). Moreover, TETRACOSANE(C24H50), (E,3R)2-BENZYLIDENE-3-HYDROXYBUTANOIC ACID (C11H1203),3Pentadecylphenol (0,2,6,10,14,18,22-Tetracosahexaene (C30H50),
1,4-Benzenediol, 2,5-bis(1,1-dimethylethyl), and (Z)-7Hexadecenal(C16H300) are exhibited antifungal, antibacterial, and antiviral activity.

\section{DISCUSSION}

Nowadays, the study of the organic compounds for biological activity from natural resources has increased. The combination of GC-MS is a great technique for separation and identification of volatile and semi- 
Table 2: Antipyretic and antiparasitic compounds present in $S$. jambos leaf extract

\begin{tabular}{|c|c|c|c|}
\hline S. No. & Compound name & $\begin{array}{l}\text { Structure of the } \\
\text { compound }\end{array}$ & Biological activity \\
\hline 1 & 1-Deoxy-d-mannitol & $\mathrm{OH}$ & Antipyretic activity \\
\hline 2 & 3-methyl-2-methylsulfanyl-5-nitro-6-pyridin-4-ylpyrimidin-4-one & & Antipyretic activity \\
\hline 3 & 3-Pentadecylphenol (3-n-Pentadecylphenol) & & Antipyretic activity \\
\hline 4 & 2-BIPHENYLENECARBOXYLIC ACID & & Antiparasitic and \\
\hline 5 & Quinoline-3-carboxylic acid( 3-Quinolinecarboxylic acid) & & $\begin{array}{l}\text { Antiparasitic and } \\
\text { antimalarial activity }\end{array}$ \\
\hline 6 & Stigmast-5-en-3-ol, Azuprostat; Nimbosterol;.alpha.-Phytosterol & & Antipyretic activity \\
\hline
\end{tabular}

S. jambos: Syzygium jambos

Table 3: Antibacterial, antifungal and antiviral compounds present in $S$. jambos leaf extract

\begin{tabular}{|c|c|c|c|}
\hline S. No. & Compound name & Structure of the compound & Biological activity \\
\hline 1 & TETRACOSANE,(N-Tetracosane) & & $\begin{array}{l}\text { Drugs for dermatological problem, } \\
\text { antibacterial activity }\end{array}$ \\
\hline 2 & (E,3R)-2-BENZYLIDENE-3-HYDROXYBUTANOIC ACID & & Drugs for dermatological problem \\
\hline 3 & 3-Pentadecylphenol (Phenol, 3-pentadecyl) & & $\begin{array}{l}\text { Drugs for dermatological problem, } \\
\text { antibacterial activity }\end{array}$ \\
\hline 4 & $\begin{array}{l}\text { 2,6,10,14,18,22-Tetracosahexaene, } \\
\text { 2,6,10,15,19,23-hexamethyl }\end{array}$ & & $\begin{array}{l}\text { Drugs for dermatological problem, } \\
\text { antibacterial activity }\end{array}$ \\
\hline 5 & (Z)-7-Hexadecenal, 7-Hexadecenal, (Z) & & Antiviral activity, organic fertilizer \\
\hline 6 & 1,4-Benzenediol, 2,5-bis (1,1-dimethylethyl) & & $\begin{array}{l}\text { Drug for dermatological disorders, acting } \\
\text { as analgesics }\end{array}$ \\
\hline
\end{tabular}

S. jambos: Syzygium jambos

volatile bioactive compounds [18]. In general, the reliability of medicinal plant for its usage is evaluated by correlating the phytochemical compounds with their biological activities [19].
In the present exploration, totally 45 bioactive chemical constituents were identified in methanolic leaf extract of $S$. jambos having biological properties. From the GC-MS investigation, too many numbers of 
bioactive compounds were present in the leaf extract which is mentioned in Table 1. 1-Deoxy-d-mannitol, 3-methyl-2-methylsulfanyl-5-nitro6-pyridin-4-ylpyrimidin-4-one, 3-Pentadecylphenol, 2-biphenylene carboxylic acid, Quinoline-3-carboxylic acid and Stigmast-5-en-3-ol are important phytoconstituents which have antipyretic and antiparasitic activities. Hexadecanoic acid, Octadecanoic, and Octadecadienoic compounds are observed in our study; these compounds are previously identified in different plant extracts reported. Hexadecanoic acid had been reported in alcohol extract of the leaves of Kigelia pinnata [20] and M. officinalis $[21,22]$. We identified 17 compounds with n-Hexadecanoic acid and Octadecanoic acid as the major compounds in the leaves of Cleistanthus collinus. GC-MS analysis of ethyl acetate extract of Goniothalamus umbrosus revealed the presence of n-Hexadecanoic acid [23]. n-hexadecanoic acid, Hexadecanoic acid, Phytol, 9, 12-Octadecadienoic acid, 9, 12, 15-Octadecatrienoic. There is a growing awareness of the importance of the phytochemical components and their biological activities [24,25].

\section{CONCLUSION}

$S$. jambos is a tree used as medicine by our ancient people; however, there are no reports on the thorough phytochemical analysis of the plant. GC-MS analysis reported the important biological components presented in our selected plant. Secondary metabolites will be rich in plants which are widely used in traditional medicine to treat and cure various ailments as well as in the modern medicine. The secondary metabolites such as alkaloids, phenols, tannins, and flavonoids are acted against different biological problems. The present investigation has given preliminary information of phytocompounds present in $S$. jambos leaf extract which is useful for the human community. Further investigations are needed in silico for these bioactive compounds which may add new knowledge to the information of S. jambos which is useful for pharmacological evaluation.

\section{ACKNOWLEDGMENTS}

The authors would like to thank the Central Instrument Facility, PSG College of Arts and Science, Coimbatore, for providing required facilities to carry out this research work.

\section{REFERENCES}

1. Briskin DP. Medicinal plants and phytomedicines. Linking plant biochemistry and physiology to human health. Plant Physiol 2000;124(2):507-14

2. Thomas E, Aneesh TP, Thomas DG, Anandan R. GC-MS analysis of phytochemical compounds present in the rhizomes of Nervilia aragoana gaud. Asian J Pharm Clin Res 2013;6(3):68-74.

3. Divya R, Manimegalai K. Preliminary phytochemical screening, and GC-MS profiling of ethanolic flower extract of Calotropis gigantea Linn. (Apocynaceae). J Pharm Phytochem 2013;2(3):28-32.

4. Sudha SS, Rajamanickam K, Rengaramanujam J. Microalgae mediated synthesis of silver nanoparticles and their antibacterial activity against pathogenic bacteria. Indian J Exp Biol 2013;51(5):393-9.

5. Sudha SS, Karthic R, Rengaramanujam J, Athulya. Antimicrobial activity of Spirulina platensis and Aphanothece sp. On selected clinical bacterial isolates and its antioxidant activity. South Asian J Biol Sci
2011;1(2):87-98

6. World Health Organization. WHO Report, Technical Report WHO/ EDM/TRM/2002.21. Geneva: World Health Organization; 2002. p. 19.

7. Kaushik P, Lal S, Rana AC, Kaushik D. GC-MS analysis of bioactive constituents of Pinus roxburghii Sarg. (Pinaceae) from Northern India. Res J Photochem 2014;8(2):42-6.

8. Robertson DG. Metabonomics in toxicology: A review. Toxicol Sci 2005;85(2):809-22.

9. Kell DB, Brown M, Davey HM, Dunn WB, Spasic I, Oliver SG. Metabolic footprinting and systems biology: The medium is the message. Nat Rev Microbiol 2005;3(7):557-65.

10. Martinez SB, Valle MJ. Storage stability and sensory quality of Syzygium cumini Linn. Anthocyanins as a food colorant. UP Home Econ J 1981;9:1.

11. CSIR. A Wealth of India-Raw Materials. Vol. X. New Delhi: CSIR; 1976. p. 100-4

12. Atta-Ur-Rahman, Zaman K. Medicinal plants with hypoglycemic activity. J Ethnopharmacol 1989;26(1):1-55.

13. Teixeira CC, Rava CA, Mallman da Silva $\mathrm{P}$, Melchior R, Argenta R, Anselmi F, et al. Absence of antihyperglycemic effect of jambolan in experimental and clinical models. J Ethnopharmacol 2000;71(1-2):343-7.

14. Boericke W. Pocket Manual of Homoeopathic Materia medica. New Delhi: B. Jain Publishers; 1988.

15. Allen TF. The Encyclopedia of Pure Materia medica. New Delhi: B. Jain Publishers; 1982.

16. Suo MR, Yang JS. Survey in studies on chemical constituents of sesquiterpene and their physiological activities in plants of Helianthus L. Chin Tradit Herb Drug 2006;37:135-40.

17. Guido F, Pier LC, Ivano M, Ammar B. Essential oils of the aerial parts of three Salvia species from Jordan: Salvia lanigera, S. spinos and S. syriaca. Food Chem 2007;100:732-5.

18. Grover N, Patni V. Phytochemical characterization using various solvent extracts and GC-MS analysis of a methanolic extract of Woodfordia fruticosa (L) Kurz. Leaves. Int J Pharm Pharm Sci 2013;5(4):291-5

19. Saxena M, Mir AH, Sharma M, Malla MY, Qureshi S, Mir MI, et al. Phytochemical screening and in-vitro antioxidant activity isolated bioactive compounds from Tridax procumbens Linn. Pak J Biol Sci 2013;16(24):1971-7.

20. Grace OM, Light ME, Lindsey KL, Moholland DA, Staden JV, Jader AK. Antibacterial activity and isolation of antibacterial compounds from the fruit of the traditional African medicinal plant, Kigelia africana. S Afr J Bot 2002;68(2):220-2.

21. Sharafzadeh S, Khosh-Khui M, Javidnia K. Aroma profile of leaf and stem of Lemon balm (Melissa officinalis L). Grown under greenhouse conditions. Adv Environ Biol 2011:5(4):547-50.

22. Parasuraman S, Raveendran R, Madhavrao C. GC-MS analysis of leaf extracts of Cleistanthus collinus Roxb. (Euphorbiaceae). Int J Pharm Sci 2009;1(2):284-6.

23. Ibraham AS, Abdull AB, Elhassan MM, Mohan S, Ibrahim MY, Mariod AA, et al. GC-MS determination of bioactive components and antibacterial properties of Goniothalamus umbrosus extracts. Afr J Biotech 2009;8(14):3336-40.

24. Sumner LW, Mendes P, Dixon RA. Plant metabolomics: Large-scale phytochemistry in the functional genomics era. Phytochemistry 2003;62(6):817-36.

25. Ashok K, Jayaprakash P. Screening of active phytocompounds by GC MS study and antimicrobial activity in the stem of Santalum album. Int J Curr Pharm Res 2012;4(3):43-4. 